\title{
Probiotics in the treatment of acute rotavirus diarrhoea. A randomized, double-blind, controlled trial using two different probiotic preparations in Bolivian children
}

\author{
Giuseppe Grandy ${ }^{1,3^{*}}$, Marcos Medina ${ }^{1 \dagger}$, Richard Soria ${ }^{1,2 \dagger}$, Carlos G Terán ${ }^{1 \dagger}$, Magdalena Araya ${ }^{3+}$
}

\begin{abstract}
Background: Evidence suggests that probiotics reduce rotavirus diarrhoea duration. Although there are several probiotic strains potentially useful, daily practice is often limited by the type and number of products locally available. In general, information about combined products is scarce. In this study we compare the effect of two probiotic products in the treatment of diarrhoea in children less than 2 years of age.
\end{abstract}

Methods: A Randomized double-blind controlled clinical trial in children hospitalized for acute rotavirus diarrhoea, in the Paediatric Centre Albina Patino, Cochabamba, Bolivia.

Participants were children aged 1 - 23 months, who were randomly assigned to receive one of three treatments: Oral rehydration therapy plus placebo; Oral rehydration solution plus Saccharomyces boulardii; or Oral rehydration solution plus a compound containing Lactobacillus acidophilus, Lactobacillus rhamnosus, Bifidobacterium longum and Saccharomyces boulardii. Sample size was 20 per group and the outcomes were duration of diarrhoea, of fever, of vomiting and of hospitalization.

Results: 64 cases finished the protocol. On admission, patients' characteristics were similar. Median duration of diarrhoea ( $p=0.04$ ) in children who received the single species product (58 hours) was shorter than in controls (84.5 hrs). Comparing children that received the single probiotic product and controls showed shorter duration of fever (18 vs 67 hrs) ( $p=0.0042)$ and the mixed probiotic of vomiting ( 0 vs 42.5 hrs) ( $p=0.041$ ). There was no effect on duration of hospitalization ( $p=0.31$ ). When experimental groups were merged, statistical significance of changes increased (total duration of diarrhoea, fever and vomiting $P=0.025, P=0.025$ and $P=0.014$, respectively).

Conclusions: Both products decreased the duration of diarrhoea compared to oral rehydration solution alone. This decrease was significant only for the single species product which also decreased the duration of fever. With the multiple species product there was no vomiting subsequent to the initiation of treatment. The quantity of probiotic bacteria needed for optimum treatment of gastroenteritis remains to be determined, particularly when multiple species are included in the product.

Trial Registration: ClinicalTrials (NCT): NCT00981877

\section{Background}

Acute gastroenteritis is an infectious syndrome that represents the first cause of hospitalization in children.

\footnotetext{
* Correspondence: ggrandy@inta.cl

† Contributed equally

${ }^{1}$ Paediatric Centre Albina Patiño, Department of Gastroenterology and

Nutrition, Department of Infectology. Cochabamba, Bolivia

Full list of author information is available at the end of the article
}

Cohort studies show that nearly all children suffer at least one rotavirus infection before reaching 5 years of age, independent of their socioeconomic status [1]. Below one year of age, rotavirus represents the main etiologic agent, both in developed and developing countries [2-4]. Globally, this agent is responsible for approximately 600.000 deaths per year [2], 82\% of which occur in less developed areas. In Latin America, 
rotavirus gastroenteritis represents 16 to $52 \%$ of cases [5] whereas in Bolivia, in 2008 the Health Sentinels System reported that below 5 years of age rotavirus was the main cause of severe gastroenteritis in children, affecting all socioeconomic conditions; thus, rotavirus was responsible for $40 \%$ of hospitalizations and $50 \%$ of deaths [6]. In 1989, a study by Lopez et al in Cochabamba, Bolivia, described that rotavirus was found in $22.5 \%$ of cases admitted for acute diarrhoeal disease [7]. More recently, a study conducted in 2007 also in Cochabamba, confirmed the high frequency (19\%) of rotavirus in children admitted for acute diarrhoea [8].

Treatment of diarrhoea basically consists of replacing lost fluids by means of oral rehydration solutions $[9,10]$; in order to minimize the nutritional impact, treatment aims at shortening the period of fluid losses (diarrhoea and vomiting) and total time of diarrhoea. Although oral rehydration solutions successfully avoid death associated with dehydration and acidosis, they are not effective in shortening the duration of rotavirus-induced diarrhoea and of high fluid losses [11-14]. Testing different strategies to help in this direction, probiotics appear as one of the alternatives currently under discussion [15]. That probiotics may shorten the time of diarrhoea and therefore the time of rotavirus excretion $[11,15]$ is of epidemiological relevance and deserves study.

Although there are several probiotic strains that could be used for treatment, in daily practice we are often limited by the type and number of products locally available. In general, information about combined products is scarce. With this in mind, in this study we compared the efficacy of two commercially available products, one containing $S$ boulardii (single species product) and the other combining L. acidophilus, L. rhamnosus, B. longum (multiple species product), in children with rotavirus associated diarrhoea.

\section{Methods \\ Design}

This was a prospective, double blind, randomized protocol conducted in children 1 to 23 months of age, hospitalized for acute diarrhoea at the Paediatric Centre Albina Patiño (CPAP) between July 2007 and February 2008 in Cochabamba - Bolivia. These children were evaluated for rotavirus, as well as for bacterial pathogens and parasites. Parents received detailed information about the study and those who agreed to participate signed an informed consent. The protocol was reviewed and approved by the Ethics Committee of CPAP; also, we explained the study in detail to the professionals in charge of the patients care such that they would be motivated and willing to follow the protocol strictly.
Operational definition of acute diarrhoea was defined as the presence of at least three bowel movements more than the normal number for the child and/or presence of watery stools per day, plus a latex test positive for rotavirus within 24 hour prior to hospitalization or within 6 hours after hospitalization. Exclusion criteria were Weight/Height (WHO standards, 2006,) [16] at or below -3SD, dehydration $>10 \%$ (because patients received iv fluids), severe electrolytic imbalance (hypokalemia $<3.5 \mathrm{mEq} / \mathrm{L}$, hypernatremia $<145 \mathrm{mEq} / \mathrm{L}$ ), detection of bacterial and/or parasitic agents of diarrhoea in the stools, detection of other infections (sepsis, pneumonia, urinary infection), diagnosis of immune deficiency, administration of antibiotics, anti diarrheal drugs or probiotics during the 7 days prior to admission to the protocol.

On admission to the study data about full clinical history, physical examination, nutritional status, dehydration, fever, oral tolerance, and stools characteristics, were recorded. After the patient clinically stabilized and maintained hydration for at least 3 hours (within approximately 24 hours), cases were randomized to one of three groups (figure 1): Group GC received oral rehydration solution (ORS) and a placebo, Group GB received ORS plus $S$ boulardii and group GARLB received ORS plus the combined probiotic product L. acidophilus, L. rhamnosus, B. longum and S. boulardii (table 1). Placebo and probiotic products had similar colour and taste. They were administered for 5 days, twice daily, dissolved in $20 \mathrm{ml}$ of water, as indicated by the manufacturer. During the first 48-72 hours the patients remained in hospital; then the attending physician decided when the child was discharged, on the basis of the his/her clinical condition and absence of diarrhoea, vomiting or fever. After discharge the infants were monitored once a day until 5 days of treatment were completed. Controls was performed at the hospital, by the attending physician, recording probiotic intake, frequency and appearance of stools, presence of fever and other relevant clinical features.

Diet

All children received the same diet; those below 6 months of age maintained breast feeding, adding infant formula (NAN $1^{\circ}$, Nestle, Vevey, Switzerland) only when the mother could not be present. After 6 months of age and in addition to breast feeding and formula, infants were offered porridge prepared with chicken, rice, and vegetables (carrots and potatoes).

\section{Variables}

The study variable was defined as length of diarrhoea (in hours), from admission to the first formed stool; presence of stools and their consistency was checked every four hours, classifying them in liquid, semi-liquid, soft 


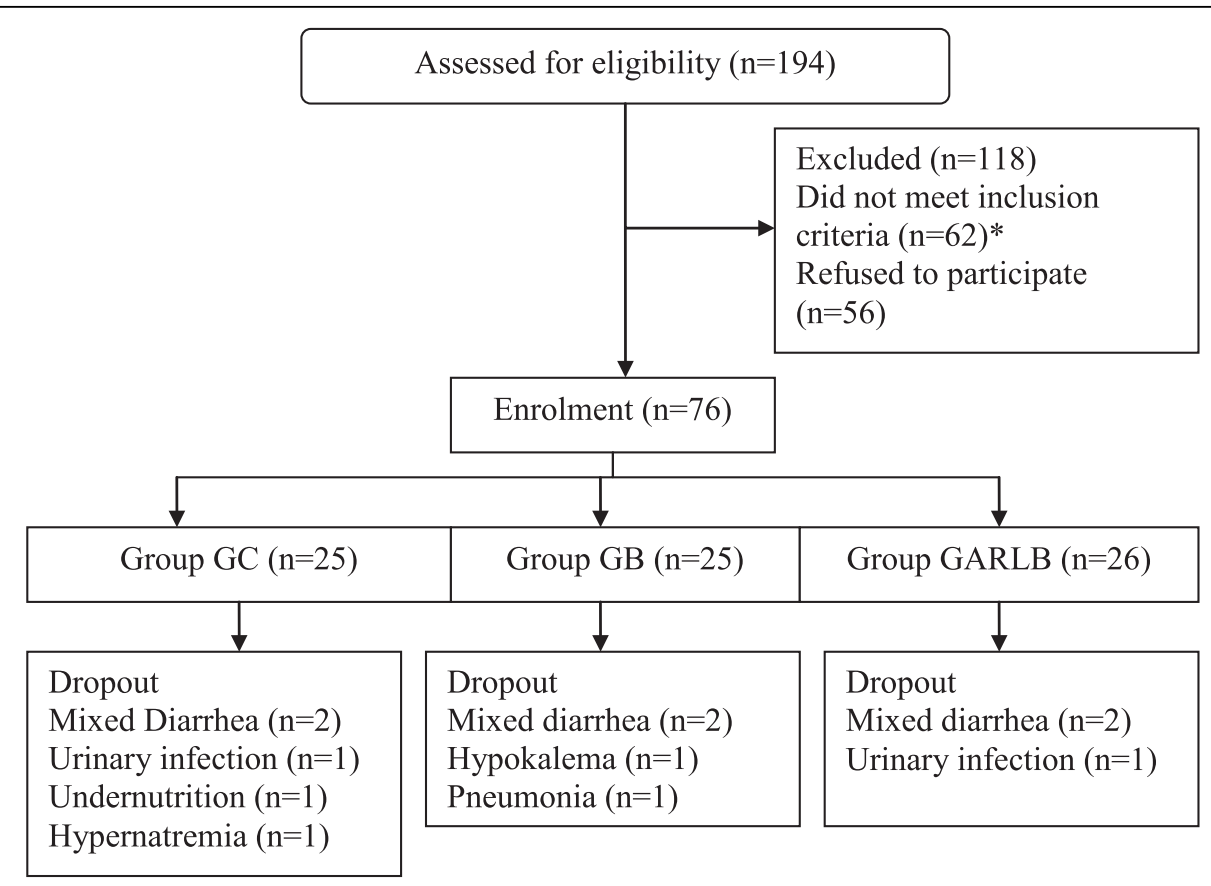

\begin{abstract}
*Excluded subjects: Eight infants were admitted to hospital with acute mixed diarrhoea, (rotavirus and amoebiasis), ten were admitted with a diagnosis of moderate acute undernutrition and acute diarrhoea, fifteen consumed antibiotics during the seven days before their hospitalization, eighteen consumed probiotic, and eleven use some kind of antidiarrheal medication.
\end{abstract}

Figure 1 Flow Diagram. Flow of participants through trial.

and formed. Secondary variables were vomiting (measured in hours from admission to the last recorded emesis), duration of fever $\left(>38^{\circ} \mathrm{C}\right.$ rectal temperature, measured every six hours from admission to discharge). Height was measured in centimetres on admission and discharge; weight was measured every eight hours using a scale with $0.5 \mathrm{~g}$ increments and up to $15 \mathrm{~kg}$ capacity. Procedures

Blood count included haemoglobin and peripheral white blood count and differential formula; determination of

Table 1 Micro organisms load according to the manufacturer, administration, and main characteristic of probiotic products analyzed

\begin{tabular}{lllc}
\hline Group & Microorganisms & Dose (twice daily) & Price $\mathbf{( \$ )}$ \\
\hline GARLB & L. acidophilus, & $6.625 \times 10^{7}$ lyophilized cells/dose & 8.71 \\
& L. rhamnosus, & $3.625 \times 10^{7}$ lyophilized cells/dose & \\
& B. longum, & $8.75 \times 10^{6}$ lyophilized cells/dose & \\
& S. boulardii & $1.375 \times 10^{7}$ lyophilized cells/dose & \\
\hline GB & S. Boulardii & $4 \times 10^{10}$ lyophilized cells/dose & 11.43 \\
\hline
\end{tabular}

*Price corresponds to complete treatment course at the time of the study. semi quantitative CRP was performed using the commercial kit Humatex ${ }^{\oplus}$ CRP(Human Gessellshaff, Wiesbaden, Germany); sodium, potassium and calcium in plasma using Photometry using Sherwood ${ }^{\circledR}$ Model 410 Classic Flame Photometer Range (Sherwood Scientific Limited, Cambridge, UK); latex test for rotavirus using Rida $^{\oplus}$ Quick Rotavirus/Adenovirus Combi (R-Biopharm AG, Darmstadt, Germany) and parasitological assessment by PAF technique by Lugol method [17]. Stool culture was performed for enteropathogenic, toxigenic, enteroadherent, enteroaggregative, invasive and enterohemorrhagic E coli, Salmonella typhi and Shigella sp, applying routine procedures (Agar base, MacConkey Agar, SS agar and Tetrahionate Broth Base. Bacto Difco $^{\circledR}$, Kansas, USA).

\section{Sample size}

This was calculated using the data published by Guarino [18], who described the effects of a product that combined three probiotics in children with rotavirus diarrhoea and found that diarrhoea decreased from $120 \pm$ 30 to $96 \pm 30$ (24 hours decrease); using 0.8 power, 0.05 (one-sided) significance and assuming 24 hours 
difference between the experimental and control groups the sample size was calculated as 20 cases per group.

\section{Statistical analysis}

This included the comparison between the control and each of the intervention groups and between the two intervention groups, using non parametric KruskallWallis testing for comparison of medians in continuous variables and Mann-Whitney U test. Chi square was applied to categorical variables. An additional analysis compared the control group with the merged intervention groups, using Mann - Whitney U test. Data were processed using Microsoft excel and STATA 1.0

\section{Results}

As shown in the algorithm (figure 1), a total of 194 children below 2 years of age were admitted during the study period; 76 fulfilled the protocol inclusion and exclusion criteria; 12 patients were excluded from analysis: in six, other etiologic agents were found together with rotavirus (amoebas $=4$, Shigella $s p=2$ ); 2 patients developed $\mathrm{E}$ coli associated urinary infection; in one pneumonia was diagnosed; one developed bilateral oedema and kwashiorkor; 2 patients developed severe vomiting for several days and maintained electrolytic imbalance; thus, the final number of patients analyzed was 64. General characteristics of patients excluded were not different from those that completed the study period (data not shown).

Sex, age and characteristics of diarrhoea prior to admission appear in table 2.

Total duration of diarrhoea was significantly shorter in children receiving $S$ boulardii $(\mathrm{P}=0.04)$ and the decrease observed in those receiving GARLB was non significant $(\mathrm{P}=0.06)$ (table 3$)$; differences were not significant either between the two intervention groups (table 3). Although the number of children with fever was similar in the three groups, duration of fever was significantly shorter in the group receiving $S$ boulardii (as compared to controls) $(\mathrm{P}=0.0042)$, whereas no changes were observed in group GARLB (also compared to controls). In the same way, the number of children with vomiting was not different between the three groups, but group GARLB showed vomiting for a significant shorter time than controls $(\mathrm{P}=0.041)$ (table 2$)$. Diarrhoea, vomiting or other complications were detected after hospital discharge (data not shown). When the merged intervention groups were compared with controls (Table 4), total duration of diarrhoea, fever and vomiting were significantly shorter, $(\mathrm{P}=0.025$, $\mathrm{P}=0.025$ and $\mathrm{P}=0.014$, respectively).

\section{Discussion}

Results show that $S$ boulardii diminished the time of diarrhoea by $31.4 \%$ and shortened time with fever by 73\% (table 3). Children receiving the multiple species product tended to have less time with diarrhoea and no patients vomited after the treatment was started. In previous studies that administered multiple species products similar to the one we used, other authors found a rather more pronounced effect, 30 hours $[14,19]$ and 30-36 hours reduction in diarrhoeal duration [20-23], in comparison with the 26 hours reduction we found. Infants hospitalized in our study were admitted with severe diarrhoea and had intense clinical manifestations in comparison to outpatients with rotavirus diarrhoea; this could explain the less intense results obtained. Although not significant, we consider relevant the trend

Table 2 Basal characteristics of groups and secondary outcomes

\begin{tabular}{|c|c|c|c|c|}
\hline & $\begin{array}{c}\text { GC Group } \\
n=20\end{array}$ & $\begin{array}{c}\text { GARLB Group } \\
n=23\end{array}$ & $\begin{array}{c}\text { GB Group } \\
n=21\end{array}$ & $P$ value \\
\hline Boys (\%) & $9(45)$ & $15(65)$ & $12(57)$ & $0.40^{*}$ \\
\hline Age, months (IQR) & $11(8.5)$ & $6(5)$ & $8(7)$ & $0.08^{\dagger}$ \\
\hline Weight, gr. (IQR) & $7775(1769.5)$ & $7652.5(2765)$ & $7800(2115)$ & $0.92^{\dagger}$ \\
\hline Duration(IQR) of diarrhoea before treatment (hours) & $48(24)$ & $72(36)$ & $48(48)$ & $0.17^{\dagger}$ \\
\hline Median hours of hospitalization (IQR) & $89.5(117)$ & $72(36)$ & $60(41)$ & $0.31^{\bigotimes}$ \\
\hline $\mathrm{N}^{\circ}(\%)$ of children with fever & $19(95)$ & $21(91)$ & $18(86)$ & $0.59^{*}$ \\
\hline Median (IQR) duration of fever (hours) & $67(60)$ & $48(36)$ & $18(53)$ & $0.0042^{\dagger}$ \\
\hline $\mathrm{N}^{\circ}(\%)$ of children vomiting & $13(65)$ & $10(43.5)$ & $11(52.4)$ & $0.37^{*}$ \\
\hline Median (IQR) duration of vomiting (hours) & $42.5(69.5)$ & $0(25)$ & $4(44)$ & $0.041^{\ddagger}$ \\
\hline
\end{tabular}

Patients' characteristics on admission. Duration of hospitalization, of fever and of vomiting after treatment.

$\mathrm{IQR}=$ Intercuartile Range

* Chi square test

† Kruskall - Wallis test

$\triangle$ Kruskall - Wallis test, adjusted $p$ value, median comparison between $G C$ and GB groups.

‡ Kruskall - Wallis test, adjusted $p$ value, median comparison between GC and GARLB groups. 
Table 3 Principal Outcome

\begin{tabular}{llcc}
\hline Group & Treatment & Median (IQR) duration (hrs.) & ${ }^{*} \mathbf{p}$ value \\
\hline GARLB & L. acidophilus, L. rhamnosus, B. longum, S. boulardii & $60(40)$ & $0.06^{\dagger}$ \\
\hline GB & S. boulardii & $58(41)$ & $0.04^{\dagger}$ \\
\hline GC & Control group & $84.5(94)$ & - - \\
\hline
\end{tabular}

Duration of diarrhoea after treatment.

$\mathrm{IQR}=$ Intercuartile Range

* $p$ value: comparison of median with control group.

† U Mann - Whitney test.

to diminish time of diarrhoea in the group receiving the multiple probiotic products, because decreasing severity of diarrhoea may help reducing the nutritional impact of the diarrhoeal episode.

Other factors such as poor nutritional status, severe diarrhoea, severe dehydration, should not be confounding variables in this protocol because they were all exclusion criteria. Reports in the literature about children with rotavirus diarrhoea refer mainly to cases managed as outpatients. This study provides evidence that probiotics are also helpful in cases with less than $10 \%$ dehydration that require hospitalization. It is worth noting that in this study, despite one day less of diarrhoea, the total length of hospital admissions did not decrease. This was mainly due to requests of mothers and fathers to maintain the child one more day under observation in hospital because, living far from hospital; they feared their child would need to be readmitted to hospital.

Effects of probiotics on vomiting are not clear. Some studies have reported no effects [24] whereas other authors report a significant decrease on time of vomiting [25] or a transitory effect, observed only during some days of the episode [26]. Our results support the effect of probiotics on vomiting, showing decreased time of vomiting in the intervention groups as compared with controls (zero versus 40 hours). However only in the multiple species product-treated group the shorter time of vomiting reached significance. Furthermore, children receiving the single species product had almost 50 hours less fever than the control group. This last feature is in contrast to studies by other authors and also the results of a study conducted in our hospital comparing Nitazoxanide to probiotics, none of which detected less time with fever [27].

This study compared two probiotic products, both readily available in Bolivia, one with a single species of probiotic bacteria and the other with multiple species of probiotic bacteria. The former contains higher total concentrations of bacteria despite having only one species and yielded better results. This raises the question as to whether larger doses of one probiotic bacterial strain are more efficient than multiple species in smaller numbers.

The effect of different probiotic species and strains on diarrhoea is currently well accepted [28-32]; however, the dose required to obtain the best results is less clear. In a recent study by Fang et al [33]L. rhamnosus reduced faecal excretion of rotavirus in a dose dependent fashion; authors concluded that the minimal dose required to have a positive effect was at least $6 \times 10^{8}$ CFU, which coincides with other authors [34]. In a recent metanalysis by Guandalini [31] the recommended dose was at least $5 \times 10^{9} \mathrm{CFU}$. Other authors found no effect in duration of diarrhoea using $1 \times 10^{7}$ L. rhamnosus [28]. When we analyzed the products used in our study, we found that the mixture of probiotics included a total amount of bacteria of $1.25 \times 10^{9}$; estimating the individual dosing of each probiotics present, they were well below the amount described as effective. The fact that we found positive effects on time of diarrhoea, of vomiting and of fever suggests that the total amount of bacteria present in the product indeed influences the results, but it also suggests that adequate numbers, as it

Table 4 Comparison of the merged intervention groups with controls

\begin{tabular}{lccc}
\hline & $\begin{array}{c}\text { Control Group } \\
\mathbf{n = 2 1}\end{array}$ & $\begin{array}{c}\text { Intervention Group* } \\
\mathbf{n}=\mathbf{4 3}\end{array}$ & p value** \\
\hline Median hours of hospitalization (IQR) & $89.5(117)$ & $76(48)$ & 0.13 \\
\hline Median hours of diarrhoea (IQR) & $84.5(94)$ & $60(40.5)$ & 0.025 \\
\hline Median (IQR) duration of fever (hours) & $67(60)$ & $46.5(50.5)$ & 0.025 \\
\hline Median (IQR) duration of vomiting (hours) & $42.5(69.5)$ & $0(33)$ & 0.014 \\
\hline
\end{tabular}

Duration of diarrhoea, hospitalization, fever and vomiting

$\mathrm{IQR}=$ Intercuartile Range

* $=$ Intervention group represents the addition of the two groups receiving probiotic products

**Mann - Whitney U Test 
was the case of the single probiotic, yields better results than a mixture in lesser numbers. Discussing the dose provided by each commercial product is relevant because there is evidence suggesting that the effect obtained is dose dependent [32,35], the higher the dose the clearer effect. However, studies of adverse reactions also seem related to probiotic dosing, therefore, the appropriate amounts of bacteria should be established for each probiotic when administered in mixtures, such as that they are best inducing the effect and at the same time are safe for the patient.

\section{Conclusions}

In summary, results of this study support the use of probiotics in treating rotavirus diarrhoea. They would be especially relevant in societies where diarrhoea and malnutrition have high prevalence; decreasing time of diarrhoea, of vomiting and of fever will help diminishing (and/or preventing) malnutrition secondary to acute diarrhoea.

However, studies of adverse reactions also seem related to probiotic dosing, therefore, the appropriate amounts of bacteria should be established for each probiotic when administered in mixtures, such as that they are best inducing the effect and at the same time are safe for the patient.

\section{Acknowledgements}

This work was funded by the Albina Patino Foundation; an independent, non profit foundation created by Simon I. Patino.

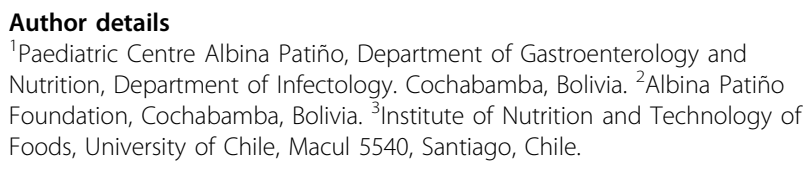

\section{Authors' contributions}

GGA conceived of the study, participated in the design of the study, supervision of the research group, participated in the collection data, performed the statistical analysis and drafted the manuscript. MMB participated in the design of the study and drafted the manuscript. RSM participated in the design of the study and performed the statistical analysis. CTM participated in the supervision of the research group, and participated in the collection data. MAQ participated in the coordination and helped to draft the manuscript. All authors read and approved the final manuscript.

\section{Competing interests}

The authors declare that they have no competing interests.

Received: 15 December 2009 Accepted: 25 August 2010 Published: 25 August 2010

\section{References}

1. Wilhelmi I, Román E, Sánchez-Fauquier A: Viruses causing gastroenteritis. Clin Microbiol Infect 2003, 9:247-62.

2. Parashar UD, Holman RC, Clarke MJ, Bresee JS, Glass RI: Hospitalizations associated with rotavirus diarrhea in the United States, 1993 through 1995: surveillance based on the new ICD-9-CM rotavirus-specific diagnostic code. J Infect Dis 1998, 177(1):13-7.
3. de Zoysa I, Feachem RG: Interventions for the control of diarrhoeal diseases among young children: rotavirus and cholera immunization. Bull World Health Organ 1985, 63(3):569-83.

4. Panamerican Health Organization: Epidemiologic surveillance of diarrheal diseases due to rotavirus: Field guide. Washington, D.C.: OPS 2007, (ISBN $9275116237)$.

5. Kane M, Turcios R, Arvay M, García S, Bresee J, Glass J: The Epidemiology of Rotavirus Diarrhea in Latin America Anticipating Rotavirus Vaccine. Rev Panam Salud Publica 2004, 16(6):371-377.

6. Ministerio de Salud y Deportes - Bolivia: Boletín informativo epidemiológico: Situación epidemiológica del rotavirus. Julio 2008, Publicacion No 4.

7. López E, Barrera F, Saavedra J, Cona E, Aguilera G: Rotavirus in the feces of children with acute diarrhea in Cochabamba, Bolivia. Rev Chil Pediatr 1989, 60(1):34-5

8. Romero C, Iniguez V, et al: Enfermedades Diarreicas Agudas Asociadas a Rotavirus. Rev Chil Pediatr 2007, 78(5):549-558.

9. Samadi AR, Islam R, Huq Ml: Replacement of intravenous therapy by oral rehydration solution in a large treatment centre for diarrhoea with dehydration. Bull World Health Organization 1998, 76(4):319-324.

10. Koletzko $S$, Osterrieder S: Acute infectious diarrhea in children. Dtsch Arztebl Int 2009, 106(33):539-47, 11.

11. Canani RB, Cirillo P, Terrin G, Cesarano L, Spagnuolo MI, De Vincenzo A, et al: Probiotics for treatment of acute diarrhoea in children: randomised clinical trial of five different preparations. BMJ 2007, 335(7615):340.

12. Ozuah PO, Avner JR, Stein RE: Oral rehydration, emergency physicians, and practice parameters: a national survey. Pediatrics 2002, 109(2):259-61.

13. Fontaine O, Gore SM, Pierce NF: Rice-based oral rehydration solution for treating diarrhoea. Cochrane Database Syst Rev 2000, CD001264.

14. Cucchiara S, Falconieri P, Di Nardo G, Parcelii MA, Dito L, Grandinetti A: New therapeutic approach in the management of intestinal disease: probiotics in intestinal disease in paediatric age. Dig Liver Dis 2002, 34(Suppl 2):S44-7.

15. Boirivant M, Strober W: The mechanism of action of probiotic. Cur Opin Gastroenterol 2007, 23(6):679-92.

16. WHO Multicentre Growth Reference Study Group: WHO Child Growth Standards: Length/height-for-age, weight-for-age, weight-for-length, weight-for-height and body mass index-for-age: Methods and development. Geneva: World Health Organization 2006.

17. Thompson RG: A simple concentration method for the detection of parasitic ova and cysts in faeces. J Clin Pathol 1972, 25:546-547.

18. Guarino A, Canani RB, Spagnuolo MI, Albano F, Di Benedetto L: Oral bacterial therapy reduces the duration of symptoms and of viral excretion in children with mild diarrhea. J Pediatr Gastroenterol Nutr 1997, 25(5):516-9.

19. Szymanski H, Pejcz J, Jawien M, Chmielarczyk A, Strus M, Heczko PB: Treatment of acute infectious diarrhoea in infants and children with a mixture of three Lactobacillus rhamnosus strains-a randomized, doubleblind, placebo-controlled trial. Aliment Pharmacol Ther 2006, 23(2):247-53.

20. Pham M, Lemberg DA, Day AS: Probiotics: sorting the evidence from the myths. Med J Aust 2008, 188(5):304-8.

21. Htwe K, Yee KS, Tin M, Vandenplas Y: Effect of Saccharomyces boulardii in the treatment of acute watery diarrhea in Myanmar children: a randomized controlled study. Am J Trop Med Hyg 2008, 78(2):214-6.

22. Billoo AG, Memon MA, Khaskheli SA, Murtaza G, lqbal K, Saeed Shekhani M, et al: Role of a probiotic (Saccharomyces boulardii) in management and prevention of diarrhoea. World J Gastroenterol 2006, 12(28):4557-60.

23. Kurugol Z, Koturoglu G: Effects of Saccharomyces boulardii in children with acute diarrhoea. Acta Paediatr 2005, 94(1):44-7.

24. Pant AR, Graham SM, Allen SJ, et al: Lactobacillus GG and acute diarrhoea in young children in the tropics. J Trop Pediatr 1996, 42(3):162-5.

25. Raza S, Graham SM, Allen SJ, et al: Lactobacillus GG promotes recovery from acute nonbloody diarrhoea in Pakistan. Ped Infect Dis J 1995, 14(2):107-111

26. Shornikova AV, Casas IA, Isolauri $E$, et al: Lactobacillus reuteri as a therapeutic agent in acute diarrhea in young children. J Pediatr Gastroenterol Nutr 1997, 24(4):399-404.

27. Nitazoxanide VS, Terán C, Terán-Escalera C, Villarroel P: Nitazoxanide vs. Probiotics for the treatment of acute rotavirus diarrhea in children: a randomized, single-blind, controlled trial in Bolivian Children. Int J Infect Dis 2009, 13:518-523. 
28. Allen SJ, Okoko B, Martinez E, Gregorio G, Dans LF: Probiotics for treating infectious diarrhoea. Cochrane Database Syst Rev 2004, , 2: CD003048.

29. Szajewska H, Setty M, Mrukowicz J, Guandalini S: Probiotics in gastrointestinal diseases in children: hard and not-so-hard evidence of efficacy. J Pediatr Gastroenterol Nutr 2006, 42(5):454-75.

30. Szajewska H, Mrukowicz JZ: Probiotics in the treatment and prevention of acute infectious diarrhea in infants and children; a systematic review of published randomized, double-blind, placebo-controlled trials. J Pediatr Gastroenterol Nutr 2001, 33(Suppl 2):S17-25.

31. Guandalini S: Probiotics for children with diarrhea: an update. J Clin Gastroenterol 2008, 42(Suppl 2):S53-7.

32. Van Niel C, Feudtner C, Garrison MM, et al: Lactobacillus therapy for acute infectious diarrhea in children: a meta-analysis. Pediatrics 2002, 109(4):678-84.

33. Fang SB, Lee HC, Hu JJ, et al: Dose-depent effect of lactobacillus rhamnosus on quantitative reduction of faecal rotavirus shedding in children. J Trop Ped 2009, 55(4):297-301.

34. Basu S, Chatterjee M, Ganguly S, et al: Effect of Lactobacillus rhamnosus GG in persistent diarrhea in Indian children, a randomized controlled trial. J Clin Gastroenterol 2007, 41(8):756-60.

35. Reid G, Sanders ME, Gaskins HR, et al: New scientific paradigms for probiotics and prebiotics. J Clin Gastroenterol 2003, 37(2):105-118.

\section{Pre-publication history}

The pre-publication history for this paper can be accessed here: http://www.biomedcentral.com/1471-2334/10/253/prepub

doi:10.1186/1471-2334-10-253

Cite this article as: Grandy et al:: Probiotics in the treatment of acute rotavirus diarrhoea. A randomized, double-blind, controlled trial using two different probiotic preparations in Bolivian children. BMC Infectious Diseases 2010 10:253.

\section{Submit your next manuscript to BioMed Central and take full advantage of:}

- Convenient online submission

- Thorough peer review

- No space constraints or color figure charges

- Immediate publication on acceptance

- Inclusion in PubMed, CAS, Scopus and Google Scholar

- Research which is freely available for redistribution

Submit your manuscript at www.biomedcentral com/submit 